\title{
UM OLHAR PARA A AUTONOMIA DE ALUNOS QUANDO DESENVOLVEM ATIVIDADES DE MODELAGEM MATEMÁTICA
}

\author{
A LOOK AT STUDENT AUTONOMY \\ WHEN THEY DEVELOP MATHEMATICAL MODELING ACTIVITIES
}

\author{
Ronalti Walaci Santiago Martin* \\ Rodolfo Eduardo Vertuan**
}

\begin{abstract}
Resumo
Neste trabalho, apresentamos parte de um projeto de pesquisa, de caráter qualitativo, que visou investigar quais aspectos de autonomia podem ser identificados quando os alunos desenvolvem uma atividade de Modelagem Matemática. Este é parte de uma pesquisa maior, apoiada pelo Conselho Nacional de Desenvolvimento Científico e Tecnológico - CNPq, intitulada "Da passagem do quinto para o sexto ano do Ensino Fundamental: uma investigação acerca da cultura escolar, dos processos de ensino e aprendizagem e das concepções docentes e discentes", cujos dados foram coletados junto a escolas de uma cidade do oeste do Paraná. Para o tratamento dos dados, utilizamos a Análise de Conteúdo de Bardin. No contexto de uma atividade sobre a quantidade de tijolos para construir a sala de aula, identificamos os aspectos de autonomia denominados iniciativa, a capacidade de planejar as próprias ações e realizá-las e, também, a capacidade construir alternativas para a resolução de um problema.
\end{abstract}

Palavras-chave: Ações do aluno. Aprendizagem. Aspectos de autonomia. Educação Matemática.

\begin{abstract}
In this paper we present part of a qualitative research project, which aimed to investigate which aspects of autonomy can be identified when students develop a Mathematical Modeling activity. Part of a larger research supported by the National Council for Scientific and Technological Development CNPq, entitled "From the passage from the fifth to the sixth grade of elementary school: an investigation about the school culture, the teaching and learning processes and the teaching and student conceptions". The data were collected from schools in a city in western Paraná. For data processing, we used Bardin Content Analysis. In the context of an activity on the amount of bricks to build the classroom, we identified aspects of autonomy called initiative, the ability to plan one's own actions and perform them, and also the ability to build alternatives for solving a problem.
\end{abstract}

Keywords: Student Actions. Learning. Aspects of autonomy. Mathematical education.

\footnotetext{
*Universidade Estadual do Oeste do Paraná, Cascavel. E-mail: ronaltiwalaci@ hotmail.com

*** Universidade Tecnológica Federal do Paraná, Toledo. E-mail: rodolfovertuan@utfpr.edu.br
} 
Um olhar para a autonomia de alunos quando desenvolvem atividades de modelagem matemática

\section{Introdução}

O estudo que descrevemos é parte de um projeto realizado em uma cidade na região oeste do Paraná, apoiado pelo Conselho Nacional de Desenvolvimento Científico e Tecnológico, CNPq, intitulado "Da passagem do quinto para o sexto ano do Ensino Fundamental: uma investigação acerca da cultura escolar, dos processos de ensino e aprendizagem e das concepções docentes e discentes".

Consideramos a transição do quinto para o sexto ano um espaço fecundo para investigações, devido às possíveis expectativas dos alunos em relação às mudanças na cultura escolar, às mudanças de escolas (de responsabilidade municipal para uma escola de responsabilidade estadual), à mudança de um professor polivalente para a existência de professores especialistas, etc. Neste contexto, tivemos um ambiente propício para investigar a questão da autonomia no desenvolvimento de atividades de Modelagem Matemática. Levando em consideração a oportunidade de olhar para aspectos de autonomia nas atividades de modelagem desenvolvidas por estudantes da Educação Básica, procuramos, neste trabalho, investigar quais aspectos de autonomia podem ser identificados quando os alunos desenvolvem uma atividade de modelagem matemática, mais especificamente, quando investigam a situação intitulada "Tijolos: como saber se não vejo?".

Para refletir e inferir respostas acerca desta problemática de pesquisa, no ambiente em que coletamos os dados, utilizamos da pesquisa qualitativa, tendo a Análise de Conteúdo em Bardin (2002) como método. Os dados coletados, referentes ao desenvolvimento das atividades de Modelagem Matemática (registro escrito, áudio e vídeo), foram analisados por meio de aspectos de autonomia destacados da literatura. Para isso, neste trabalho, apresentamos nosso entendimento de Modelagem Matemática e Autonomia, bem como apresentamos uma descrição da atividade desenvolvida e uma análise das ações dos alunos, de dois quintos e um sexto anos, nesta atividade, tem em vista nosso interesse de pesquisa. 
Um olhar para a autonomia de alunos quando desenvolvem atividades de modelagem matemática

Salientamos que o presente trabalho é um recorte da pesquisa de mestrado do primeiro autor e, portanto, considera uma pequena parte dos dados coletados durante meses de investigação.

\section{Modelagem matemática e autonomia}

Pesquisas têm apontado para a importância da Modelagem nos ambientes de ensino e de aprendizagem da Matemática, o que pode ser verificado em artigos publicados em revistas especializadas e em eventos específicos da área, como a CNMEM (Conferência Nacional sobre Modelagem na Educação Matemática) e o ENEM (Encontro Nacional de Educação Matemática) e eventos de socialização de pesquisas, como o EBRAPEM (Encontro Brasileiro de Estudantes de Pós-Graduação em Educação Matemática) e o SIPEM (Seminário Internacional de Pesquisa em Educação Matemática).

A Modelagem Matemática tem sido realizada, portanto, desde a Educação Infantil, o Ensino Fundamental, até os cursos de Pós-Graduação. E, muito embora as atividades realizadas nos diferentes niveis de ensino partilhem do fato de os alunos investigarem, por meio de matemáticas, temas advindos da realidade, outros aspectos acabam caracterizando a atividade de acordo com a concepção de Modelagem subjacente. Malheiros (2012) afirma que:

Se olharmos para parte da literatura da Educação Matemática, as concepções de Modelagem encontradas diferenciamse em alguns aspectos e o que as distingue, basicamente, é a ênfase na escolha do problema a ser investigado, que pode partir do professor, pode ser um acordo entre professor e alunos ou então os estudantes podem escolher o assunto que pretendem investigar. Além disso, é possivel considerar que elas possuem um objetivo comum: investigar e/ou pesquisar e/ou resolver problemas da realidade (seja ela do estudante, da escola, da comunidade) utilizando, para isso, conhecimentos matemáticos (MALHEIROS, 2012, p. 3). 
Um olhar para a autonomia de alunos quando desenvolvem atividades de modelagem matemática

Dos diversos entendimentos de Modelagem Matemática, nos alinhamos com os dizeres de Almeida e Vertuan (2011) quando afirmam que entendem:

[...] a Modelagem Matemática como uma alternativa pedagógica na qual fazemos uma abordagem, por meio da Matemática, de uma situação-problema não essencialmente matemática. Por ser assim entendida, a modelagem tem com aporte maior a realização de investigações em sala de aula que tem o problema como ponto de partida, a intencionalidade na busca, as hipóteses como fatores que se colocam no caminho para indicar direções e em que diferentes resoluções matemáticas são empreendidas com vistas a resolver um problema (ALMEIDA, VERTUAN, 2011, p. 22).

Em Modelagem Matemática há a possibilidade de o aluno realizar encaminhamentos que permitam o ir e vir entre a situação cotidiana e a matemática, podendo dessa maneira, aprender novos conceitos matemáticos e revisitar os já aprendidos (MARTIN, VERTUAN, 2018).

No contexto das atividades, é preciso que os alunos se lancem às investigações, tendo atitudes proativas. Neste sentido, é que nos interessamos, de modo particular, pela questão da autonomia em atividades de Modelagem. Segundo Martins (2002),

Autonomia vem do grego e significa autogoverno, governarse a si próprio. Nesse sentido, uma escola autônoma é aquela que governa a si própria. No âmbito da educação, o debate moderno em torno do tema remonta ao processo dialógico de ensinar contido na filosofia grega, que preconizava a capacidade do educando de buscar resposta às suas próprias perguntas, exercitando, portanto, sua formação autônoma (MARTINS, 2002, p. 224).

Destaca-se na fala de Benson (2001) o papel do aluno com vistas à autonomia:

O conceito de autonomia baseia-se em uma tendência natural para que os alunos assumam o controle de sua aprendizagem. Como tal, a autonomia está disponivel para todos, 
Um olhar para a autonomia de alunos quando desenvolvem atividades de modelagem matemática

embora seja exibida de maneiras diferentes e em diferentes graus de acordo com as características únicas de cada aprendiz e cada situação de aprendizagem (BENSON, 2001, p. 1-2, trad. nossa).

Benson (2001), ao falar sobre autonomia, faz menção à aprendizagem de línguas, mas considera que a autonomia está relacionada ao fato de os alunos assumirem, em alguma medida, o controle de suas aprendizagens.

Freire (1996), por sua vez, afirma em seus escritos que:

Ninguém é sujeito da autonomia de ninguém. Por outro lado, ninguém amadurece de repente, aos 25 anos. A gente vai amadurecendo todo dia, ou não. A autonomia, enquanto amadurecimento, do ser para si, é processo, é vir a ser. Não ocorre em data marcada. É neste sentido que uma pedagogia da autonomia tem de estar centrada em experiências estimuladoras da decisão e da responsabilidade, vale dizer, em experiências respeitosas da liberdade. (FREIRE, 1996, p. 41).

A autonomia se expressa junto à sensação de liberdade para buscar algo. Freire (1996, p. 58) afirma: "É com ela, a autonomia, penosamente construindo-se, que a liberdade vai preenchendo o espaço antes habitado por sua dependência. Sua autonomia que se funda na responsabilidade que vai sendo assumida".

Pereira (2010) afirma que

[...] a adoção da modelagem matemática requer uma postura de forma a proporcionar liberdade aos estudantes. Tendo em vista que a atividade deve ser heuristica e que o grupo deve investigar situações do dia-a-dia, os estudantes precisam de liberdade para propor ideias, resolver problemas, e desenvolver outras atividades (PEREIRA, 2010, p. 120).

Corroborando com o autor, Malheiros (2015) afirma que, na Modelagem Matemática, a autonomia se apresenta como elemento fundamental de sua estrutura, onde os alunos se lançam em uma investigação, pa- 
Um olhar para a autonomia de alunos quando desenvolvem atividades de modelagem matemática

ra a qual buscam informações por meio de pesquisas, sem a qual não é possivel proceder nos processos de Modelagem.

Diante de uma revisão de literatura, buscamos construir um quadro (Quadro 1), que destaca aspectos considerados como manifestações da autonomia. Buscaremos, neste trabalho, olhar para as ações/falas dos alunos, considerando alguns destes aspectos.

Quadro 1 - Aspectos de Autonomia

\begin{tabular}{|l|l|}
\hline \multicolumn{1}{|c|}{ Autores } & \multicolumn{1}{c|}{ Aspectos de Autonomia } \\
\hline (SANT'ANA, 2009) & Imprimir orientação às suas ações. \\
\hline (FREIRE, 1996) & Tomada de decisão. \\
\hline (BERBEL, 2011) & Iniciativa. \\
\hline (BERBEL, 2011) & $\begin{array}{l}\text { Construção de alternativas para a resolução de } \\
\text { um problema }\end{array}$ \\
\hline (ZATTI, 2007) & $\begin{array}{l}\text { Capacidade de planejar as próprias ações e tam- } \\
\text { bém a capacidade de realizar as ações planeja- } \\
\text { das. }\end{array}$ \\
\hline $\begin{array}{l}\text { (CHAVES, FILHO, SEI- } \\
\text { XAS, 2018) }\end{array}$ & Buscar respostas às suas próprias perguntas. \\
\hline
\end{tabular}

Fonte: Própria dos autores

\section{Aspectos metodológicos e descrição da atividade}

Desde o contato com os professores regentes das turmas em que se daria a coleta de dados da pesquisa, até o momento das observações, foi possivel conhecer características do espaço escolar, que passamos a descrever.

$\mathrm{Na}$ escola EMAS, adentramos em um quinto ano, formado por 27 alunos e uma professora polivalente ${ }^{1}$. Dos 27 alunos, um era diagnosticado autista, necessitando de uma pessoa especializada para acompanhamento. Os alunos trabalhavam dois a dois, sinalizando para o trabalho em dupla em diversas atividades propostas pela professora. A sala de

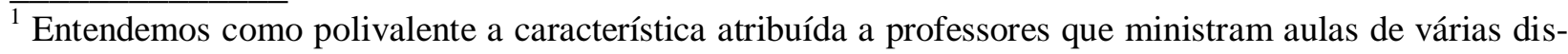
ciplinas existentes no currículo dos Anos Iniciais do Ensino Fundamental I ( $1^{\circ}$ ao $5^{\circ}$ ano).
} 
Um olhar para a autonomia de alunos quando desenvolvem atividades de modelagem matemática

aula dessa turma apresentava, em suas paredes, decorações coloridas e lúdicas para o aprendizado dos alunos. Os alunos, quando terminam o quinto ano, trocam de ambiente escolar (espaço físico) para dar continuidade aos estudos a partir do sexto ano.

$\mathrm{Na}$ escola EMADB, fomos encaminhados à uma turma de quinto ano com 28 alunos. Também nessa escola, a professora era polivalente. Os alunos se acomodam em suas carteiras em fileiras, um atrás do outro. Foi possivel notar que os lugares dos alunos, em sala de aula, foram determinados pela professora, de tal maneira que ela posicionou alguns alunos específicos em uma única fileira. As paredes da sala de aula eram preenchidas com materiais lúdicos, com vistas a contribuir e auxiliar o aprendizado dos alunos. Os alunos dessa turma, quando saem do quinto ano para o sexto ano, têm a possibilidade de estudar no mesmo espaço físico, já que a referida escola divide o mesmo espaço físico que outra estadual, denominada neste trabalho de CEJC.

No CEJC, por sua vez, fomos apresentados a uma turma de sexto ano, sendo essa composta por 29 alunos. A professora de matemática do sexto ano possui características de especialista ${ }^{2}$ e organiza sua turma em fileiras. Foi possivel notar que a sala do sexto ano, no que tange à parte física, não tem nenhum tipo de apetrecho/material nas paredes.

Portanto, os dados coletados na referida pesquisa, bem como utilizados neste artigo, referem-se a essas três turmas, cada uma de uma escola distinta, duas municipais e uma estadual. Culturalmente, os alunos da escola municipal, quinto ano, que precisam mudar de prédio físico para continuar seus estudos no sexto ano, geralmente, também iniciam seus estudos no CEJC, colégio daquela comunidade. Assim, tratam de escolas próximas umas às outras. Neste contexto, passaremos a discutir as resoluções empreendidas pelos alunos na atividade desenvolvida nas três turmas e intitulada "Tijolos: como saber se não vejo?".

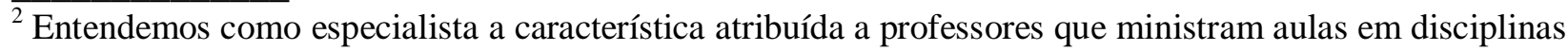
vinculadas à sua formação. Por exemplo, formado em Licenciatura em Matemática ministra aula de matemática.
} 
Um olhar para a autonomia de alunos quando desenvolvem atividades de modelagem matemática

\section{- Atividade "Tijolos: Como saber se não vejo?"}

A atividade "Tijolos: Como saber se não vejo?" surgiu na intencionalidade de os alunos olharem para algo que faz parte do cotidiano de todos, no caso, paredes de tijolos cobertas com massa e/ou tinta e dessa possibilidade pensar em estratégias para solucionar a problemática: como identificar a quantidade de tijolos que possivelmente foi utilizada para a construção da parede.

Para iniciar o desenvolvimento da atividade "Tijolos: Como saber se não vejo?" (figura 1) sugerimos que os alunos formassem seis grupos (o mesmo procedimento foi adotado em cada turma), entregamos a cada grupo um gravador de áudio e posicionamos em um canto da sala uma câmera para as filmagens.

Tijolos: Como saber se não vejo?

Em muitas construções os tijolos aparecem como Queria ter a alegria desse tijolo material fundamental. Podem ser usados para construir casas, prédios, muros, hospitais, escolas, dentre tantas outras coisas.

A sala de aula em que estudamos também é feita com tijolos, mas por causa do reboco e da tinta não conseguimos contar quantos tijolos são utilizados para erguer suas paredes.

Como podemos fazer para calcular quantos tijolos foram usados para construir a sala de aula?

Quantos tijolos foram usados para construir essa sala de aula?

Figura 1 - Atividade: “Tijolos: Como saber se não vejo?” Fonte: Própria dos autores 
Um olhar para a autonomia de alunos quando desenvolvem atividades de modelagem matemática

\section{Descrição e análise dos dados: que autonomia se revela?}

Olhamos para o desenvolvimento da atividade de um grupo de cada turma, assim, identificamos os grupos da seguinte forma; escola EMADB grupo 5ADBG4; escola EMAS grupo 5ASG1; colégio CEJC grupo 6JCG2, onde o primeiro número indica o ano escolar e o último indica o grupo de alunos considerado. Fizemos recortes sobre a transcrição do material produzido pelos alunos para apontar aspectos de autonomia que surgiram durante o desenvolvimento da atividade. Ao colocar entre os textos, “(...)", queremos nos referir ao momento em que outras discussões foram realizadas, mas não consideradas neste texto. Identificamos cada aluno com a letra "A" e um número.

\section{Produções dos alunos do grupo 5ADBG4}

No quadro dois apresentamos algumas discussões realizadas pelos alunos durante a realização da atividade "Tijolos: Como saber se não vejo?" de maneira a apresentar como se deu a investigação. Assim, na sequência do quadro 2, apontamos para o aspecto de autonomia que surgiu com evidência nas produções dos alunos, segundo nossa interpretação.

Quadro 2 - Produções dos alunos turma 5ADBG4

A1: "Professor, professor, como podemos fazer para calcular quantos tijolos foram usados para construir a sala de aula?".

Pesquisador: "E ai quanto vai ser?".

A2: "No teto não tem tijolo nenhum".

Pesquisador: "E nas paredes?".

A3: "Nas paredes temos que contar".

A1: "Nessa parede tem um metro, uns 100".

Pesquisador: "Mas vocês acham que só vai 100?".

A1: “200?”.

Pesquisador: "Quantos vocês acham que vai?". "Que tamanho tem um tijolo mais ou menos?".

A4: "Depende do tamanho da parede".

Mostraram afastando as mãos o tamanho de um tijolo. 
Um olhar para a autonomia de alunos quando desenvolvem atividades de modelagem matemática

Questionamos se era do tamanho mostrado, ou se era maior.

A3: "Pega a régua para ver".

Começaram a discutir entre si o tamanho do tijolo.

A3: "Acho que tem uns $20 \mathrm{~cm}$ ".

A1: "O tijolo que meu pai fez tem esse tamanho". Mostrou a aluna com a mão.

A1: "Professor, 19 centímetros".

Pesquisador: "Então desenhem um tijolo com mais ou menos o tamanho que vocês acham".

Enquanto explicávamos o aluno disse:

A5: "Pronto professor, já fiz o meu tijolo".

$\ldots$

Após essas discussões no grupo, trouxemos tijolos para que os alunos medissem as dimensões do tijolo.

...

Pesquisador: "O que vocês querem medir na parede?".

A5: "Quantos tijolos têm".

Pesquisador: "Isso, mas o que é preciso fazer com as paredes da sala?". "Medir o que nas paredes?".

A5: "Os tijolos".

Pesquisador: "Mas a gente consegue medir os tijolos na parede?".

A2: "Sim, é só ver nos centímetros dele".

A5: "É só a gente somar $18+18+18 \ldots$ até".

A2: "Mas um tijolo é 18 e meio". Disse o colega.

...

Após anotar as dimensões da sala pedimos que os alunos trabalhassem na problemática. Os alunos entenderam que era preciso fazer a altura da sala dividida pela altura do tijolo.

A4: "Agente descobriu que nessa parede aqui tem 21 tijolos".

Pesquisador: "Como vocês descobriram?".

A4: "A gente pegou 380 , que é $3,80 \mathrm{~m}$ e a gente pegou a medida do tijolo que é 18 , na verdade 18,5 , mas usamos 18 ".

Trabalhamos com eles como os tijolos são posicionados na parede, dessa forma fazendo a divisão não mais por 18 e sim por 13 como podemos ver a seguir.

Pesquisador: "Pensem no que a colega de vocês falou, pegue a altura que é $380 \mathrm{~cm}$, dividido por quanto?”.

A1: "18".

A4: "13". 
Pesquisador: "Isso 13". "mas porque por 13?".

A2: "Porque 13 é a altura".

...

Os alunos do grupo estavam meio perdidos nas operações. Conversaram como calcular.

A4: "Professor agora o nosso deu 29".

Pesquisador: "29 é o que?".

A1: "29 tijolos é a altura".

Fonte: Própria dos autores

Podemos destacar, no quadro 2, o aspecto de autonomia denominado "iniciativa". Para Berbel (2011) a iniciativa está relacionada ao fato de os alunos se posicionarem frente às atividades propostas, mediarem às discussões no grupo e buscarem meios de dirimir os problemas relativos à investigação. Em princípio, os alunos do grupo se posicionaram frente à atividade chamando o professor, o que denota interesse em realizá-la, levantando hipóteses apontando para a quantidade de tijolos na parede "Nessa parede tem um metro, uns 100" e depois apontando para as medidas do tijolo "Acho que tem uns $20 \mathrm{~cm}$ ". As discussões sobre o formato do tijolo foram mediadas pelos próprios alunos, com gestos inclusive, sobre como é posicionado na parede, sobre como encontrar a quantidade de tijolos "É só a gente somar $18+18+18 \ldots$ até". Chegar a possiveis soluções sobre a quantidade de tijolos usados para construir as paredes da sala também é ação que denota o aspecto "iniciativa", como quando apontam que "29 tijolos é a altura" da parede.

\section{Produções dos alunos do grupo 5ASG1}

Destacamos, no quadro 3, algumas falas dos alunos 5ASG1. Trazemos, na sequência, os aspectos de autonomia evidenciados nas ações dos alunos e apresentamos uma resolução feita pelo grupo. 
Um olhar para a autonomia de alunos quando desenvolvem atividades de modelagem matemática

Quadro 3 - Produções dos alunos turma 5ASG1

Como o tempo era pouco, em vez de achar a quantidade de tijolos para construir a sala de aula, pedimos para encontrar a quantidade de tijolos em uma parede.

Medindo com uma régua de $1 \mathrm{~m}$, acharam que a altura da sala era de 2,70 $\mathrm{m}$. Um dos alunos questionou o colega:

A1: Será que da certo fazer $2,70 \mathrm{~m}$ dividido por $18 \mathrm{~cm}$ ?

A2: Mas é por $14 \mathrm{~cm}$.

...

Os alunos do grupo queriam a régua para calcular algo.

A2: Meu Deus, cadê a régua?

A1: Acho que faz 2,70 dividido por 14 .

...

Pesquisador: Quantos tijolos vocês acharam para fazer uma parede?

A2: 19.

Pesquisador: Mas para fazer uma parede?

A aluna explicou mostrando com a mão que era para uma fileira em pé. No caso na vertical.

...

Conversaram sobre as medidas do tijolo e sobre o comprimento da sala.

Após alguns minutos questionamos o grupo:

Pesquisador: Quantos tijolos deram na altura?

A2: 19.

Pesquisador: E no comprimento?

A2: Estou achando.

Pesquisador: Quantos tijolos foram usados para a altura da sala?

A2: 19.

Pesquisador: E de assim?

Fazendo referencia ao comprimento da parede.

A2: 39.

Pesquisador: E agora o que fez com esses valores?

A2: Multiplicou.

Pesquisador: Isso, 19 vezes 39. E o que significa esse resultado?

A2: A quantidade de tijolos.

Fonte: Própria dos autores 
Um olhar para a autonomia de alunos quando desenvolvem atividades de modelagem matemática

Nesse quadro, atentamos para dois aspectos de autonomia os quais destacamos, em meio aos dizeres de Zatti (2007, p. 12), a capacidade de planejar ações e também a capacidade de realizá-las. "O primeiro aspecto está ligado à liberdade e ao poder de conceber, fantasiar, imaginar, decidir, e o segundo ao poder ou capacidade de fazer" (ZATTI, 2007, p.12). Observamos, nos áudios transcritos, a determinação das próprias ações perante a atividade, onde os alunos imaginam e ditam estratégias como dividir a altura da parede pela altura do tijolo "Acho que faz 2,70 dividido por 14", empreendendo tal planejamento.

Dividem o comprimento de uma das paredes da sala pelo comprimento do tijolo, encontrando quantas fileiras de tijolos há na sala, dividem a altura da sala pela altura do tijolo, considerando a dimensão do tijolo, $14 \mathrm{~cm}$, encontrando quantos tijolos tem cada fileira, como podemos ver em sua resolução.

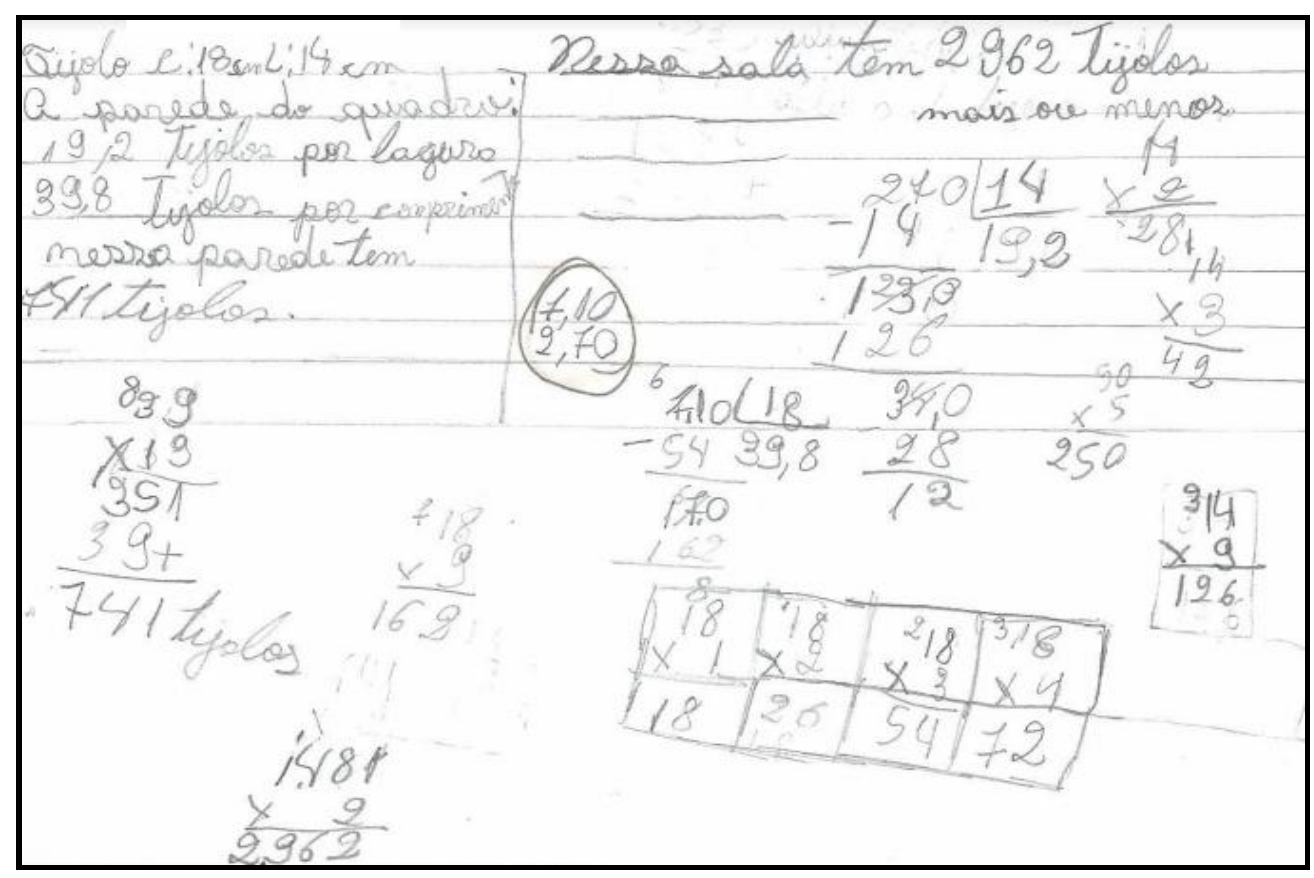

Figura 2 - Produções dos alunos turma 5ASG1

Fonte: Própria dos autores 
Um olhar para a autonomia de alunos quando desenvolvem atividades de modelagem matemática

Para finalizar, os alunos generalizam considerando que as quatro paredes têm mesmas dimensões e assim, ao encontrar quantos tijolos tem uma parede, generalizam para as quatro paredes como podemos ver na resolução.

\section{Produções dos alunos do grupo 6JCG2}

No quadro 4, descrevemos ações realizadas pelos alunos do grupo 6JCG2, as quais apontam para as alternativas construídas pelos alunos.

Quadro 4: Produções dos alunos turma 6JCG2

Para o fundo e a frente da sala duas estratégias no grupo foram usadas. Em uma primeira estratégia realizaram 600 dividido por 18, sendo 600 o comprimento da parede do fundo e da frente da sala, chegando a um valor aproximado de 33, como podemos ver na imagem 2 da aluna Al.

Tabela 3: Resolução aluna A1.

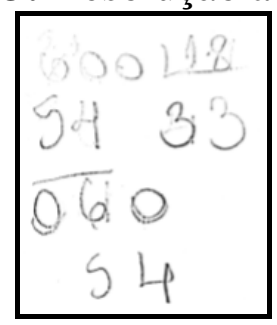

Fonte: Própria do autor

Já em uma segunda estratégia uma das alunas saiu colocando um tijolo na frente do outro na parede da frente, sobrepondo, chegando a 31 tijolos para uma fileira, como podemos ver nas falas a seguir.

Pesquisador: Como você fez isso, para achar o 31 ?

A2: Colocou um tijolo atrás do outro.

Fonte: Própria dos autores

Atentos ao que os alunos descreveram em suas falas, destacamos, em suas ações, o aspecto de autonomia construção de alternativas para a 
Um olhar para a autonomia de alunos quando desenvolvem atividades de modelagem matemática

resolução de um problema, uma vez que os alunos esboçam suas estratégias de resolução como podemos ver no quadro 4. Foram duas estratégias distintas que contribuíram para a discussão e reflexão da turma, sobre o porquê de os resultados obtidos pelas duas estratégias serem próximos.

\section{Considerações finais}

No desenvolvimento da atividade de Modelagem Matemática, "Tijolos: Como saber se não vejo?", foi possivel destacar nas ações dos alunos aspectos de autonomia. Aspectos esses derivados da participação dos alunos no desenvolvimento da atividade. Dessa forma, se evidenciam, nas ações dos alunos, a busca por resultados que representam soluções para a atividade, onde os alunos se tornam responsáveis pelo seu aprendizado. Aprendizado que se efetiva na pesquisa, na utilização de conceitos envolvendo medidas, estimativa, proporção, operações com números decimais e no desenvolvimento de estratégias.

Nos aspectos de autonomia destacados, iniciativa, a capacidade de planejar ações e também a capacidade de realizar tais ações e a construção de alternativas para a resolução de um problema, é possivel perceber a importância das ações dos alunos para o sucesso na atividade e para a aprendizagem. Ações essas de conversação, produção escrita e produções gestuais que direcionam o desenvolvimento da atividade de Modelagem e influenciam a dinâmica do grupo que realiza a investigação.

Este trabalho denota também a importância de os alunos serem protagonistas de suas aprendizagens, tendo liberdade e tempo para agir, inclusive no enfrentamento de dificuldades. Os caminhos com a Modelagem Matemática proporcionam uma estrutura importante para o desenvolvimento da autonomia do aluno, pois a atividade de Modelagem Matemática possibilitou ao aluno pesquisar, levantar ideias, construir estratégias por meio de uma situação envolvendo tijolos, objeto esse presente em grande parte de construções e que passa despercebido, atrás de rebocos e tintas.

Apontamos para as possibilidades de proporcionar autonomia aos alunos em atividades de Modelagem Matemática, corroborando para sua 
Um olhar para a autonomia de alunos quando desenvolvem atividades de modelagem matemática

formação, onde o aluno toma para si a busca por conhecimento, gerando assim, aprendizagem.

\section{Agradecimentos}

Agradecemos ao Conselho Nacional de Desenvolvimento Científico e Tecnológico (CNPq) pelo financiamento da pesquisa em que este trabalho se insere.

\section{Referências}

ALMEIDA, Lourdes M. W.; VERTUAN, Rodolfo E. Discussões sobre "como fazer" Modelagem Matemática na sala de aula. In: ALMEIDA, Lourdes M. W.; ARAÚJO, Jussara L.; BISOGNIN, Eleni. Práticas de Modelagem Matemática: relatos de experiências e propostas pedagógicas. Londrina: EDUEL, 2011. p. $19-44$.

Disponivel em: http://books.scielo.org. Acesso em: 15 set. 2017.

BARDIN, Laurance. Análise de Conteúdo. Trad. Luíz Antero Reto e Augusto Pinheiro. Porto: Edições 70, LDA, 2002.

BENSON, P. Teaching and researching autonomy in language lear ning. London: Longman, 2001.

Disponivel em: https://www.taylorfrancis.com/books/9781317862857. Acesso em: 5 fev. 2019.

BERBEL, Neusi A. N. As metodologias ativas e a promoção da autonomia de estudantes. Semina: Ciências Sociais e Humanas, Londrina, v. 32, n. 1, p. 2540, jan./jun. 2011.

CASE, Robert. Plato's Premise: fostering student autonomy. The NEA Higher Education Journal, Thought \& Action, FALL, 2002.

Disponivel em:

http://199.223.128.59/assets/img/PubThoughtAndAction/TAA_02_04.pdf.

Acesso em: 9 abr. 2019.

CHAVES, Hamilton Viana; MAIA FILHO, Osterne. N.; SEIXAS, Pablo de Sousa. Por uma educação para a autonomia de sujeitos situados no mundo. Psicologia da Educação, São Paulo, 46, p. 81-91, 1º sem. de 2018.

FREIRE, Paulo. Pedagogia da autonomia: saberes necessários à prática educativa. São Paulo: Paz e Terra, 1996. 
Um olhar para a autonomia de alunos quando desenvolvem atividades de modelagem matemática

MARTIN, Ronalti W. S.; VERTUAN, Rodolfo E. "qual a produção do milharal?": uma atividade de modelagem matemática. In: ENCONTRO PARANAENSE DE MODELAGEM EM EDUCAÇÃO MATEMÁTICA, 8, 2018. Cascavel. Anais... Resumo disponivel em: http://www.sbemparana.com.br/viiiepmem/Caderno_Resumos.pdf. Acesso em: 19 jun. 2019.

MARTINS, Angela Maria. Autonomia e educação: a trajetória de um conceito. Cadernos de Pesquisa, n. 115, p.207-232, mar.2002.

MALHEIROS, Ana Paula dos Santos. Delineando Convergências entre Investigação Temática e Modelagem Matemática. In: SEMINÁRIO INTERNACIONAL DE PESQUISA EM EDUCAÇÃO MATEMÁTICA 5., 2012, Petrópolis, Rio de Janeiro. Anais... Petrópoliz, 2012.

Disponivel em: http://www.sbembrasil.org.br/files/v_sipem/PDFs/GT10/CC25941745800_A. pdf. Acesso em: 30 set. 2017.

MALHEIROS, Ana Paula dos Santos. Contribuições de Paulo Freire para uma compreensão do trabalho com a Modelagem na Formação Inicial de Professores de Matemática. Boletim Gepem (Online), n. 64, p.1-12, jan./jun. 2014 (texto em diagramação).

Disponivel em: http://doi.editoracubo.com.br/10.4322/gepem.2015.004. Acesso em: 30 set. 2017.

PEREIRA, E. A modelagem matemática e o papel do professor de Matemática para o desenvolvimento da criatividade. In: BRANDT, F. B.; BURAK, D.; KLÜBER, T.E. Modelagem Matemática: uma perspectiva para a Educação Básica. Ponta Grossa: Editora UEPG, 2010. p. 115-126.

SANT'ANA, R. B. de. Autonomia do Sujeito: as contribuições teóricas de G. H. Mead. Psicologia: Teoria e Pesquisa, v. 25, n. 4, p. 467-477, out./dez. 2009.

ZATTI, V. Autonomia e educação em Immanuel Kant e Paulo Freire. Porto Alegre: EDIPUCRS, 2007.

Artigo recebido em: 30 jul. 2019 Artigo aprovado em: 14 nov. 2019 